\title{
A method for determination of cirrus extinction-to-backscatter ratio from
}

\section{CALIOP data}

\author{
Jingbin Zhang ${ }^{1 *}$, Jan-Bai Nee ${ }^{2}$ \\ ${ }^{1}$ Physics Department, Qufu Normal University, Qufu City 273165 , \\ Shandong Province, P. R. China,*Email: jingbin_zhang@163.com \\ ${ }^{2}$ Department of Physics, National Central University, Chung-Li, Taiwan 32054
}

\begin{abstract}
We are presenting an empirical equation to retrieve cirrus lidar ratio by using CALIOP 532 $\mathrm{nm}$ level 1 data for nighttime cases. Retrieval results have non-relationship with cirrus multiple scattering effects and not affected by the error of transmission. The average CALIPSO $532 \mathrm{~nm}$ cirrus lidar ratio over Longitude 120+/- 10 and Latitude 25+/-10 for whole year of 2008 are $21.66 \pm 0.06 \mathrm{sr}$ for the year of 2008 respectively, with the maximum bias of $9.25 \%$ for the year 2008 , the results is fairly stable and reasonable.
\end{abstract}

\section{INTRODUCTION}

Cirrus clouds play a significant role in the radiative balance of the Earth's atmospheric system, a clear understanding of their optical properties is essential for climate modeling studies. Lidars are regarded as one of the leading techniques for remotely studying the properties of cirrus clouds. Generally, lidar equation has the two unknowns backscatter and extinction coefficients as well as the multiple scattering effects, in order to be able to invert the lidar equation, they have to be related either empirical or theoretical methods[1-9]. The extinction to backscatter ratio is considered to be of special importance since it is related to microphysics and ice composition of cirrus clouds, it is controlled by the complexity of ice particle shape and aspect ratio [10].Traditionally the error of retrieved cirrus lidar ratio is dependent on the errors of multiple scattering coefficient and cirrus transmission determination [11]. In order to improve the retrieval accuracy of cirrus extinction to backscatter ratio from Mie lidar return signals, an empirical equation for determination cirrus lidar ratio was employed, the retrieval results are consistent with others'.

\section{METHODOLOGY}

The present study uses CALIOP NASA level 1 data products for the year of 2008 was used to retrieve cirrus lidar ratio over Longitude $120+/-10$ and Latitude 25+/-10. Only nighttime observations were considered in the present study, thanks to their higher signal-to-noise ratio compared to daytime observations. Lidar equation is as following:

$$
P(r)=C a \frac{\left[\beta_{m}(r)+\beta_{c}(r)\right]}{r^{2}} \exp \left[\int_{0}^{r}\left[\eta \sigma_{c}(r)+\sigma_{m}(r)\right] d r\right]
$$

Were $P(r)$ is the lidar return signals from the atmosphere at the distance $\mathrm{r}$; $C a$ is the lidar system constant; $\eta$ is cloud multiple scattering coefficient; $\beta_{m}(r)$ and $\beta_{c}(r)$ are the molecular and cloud backscatter coefficients; $\sigma_{m}(r)$ and $\sigma_{c}(r)$ are the molecular and cloud extinction 
coefficients respectively.

The cloud backscatter coefficient $\beta_{c}(r)$ is as following:

$$
\beta_{c}(r)=\frac{X(r) \exp \left[-2\left(\eta S_{c}-S_{m}\right)\right] \int_{r_{0}}^{r} \beta_{m}(r) d r}{\frac{X\left(r_{0}\right)}{\beta_{m}\left(r_{0}\right)}-2 \eta S_{c} \int_{r_{0}}^{r} X(r) \exp \left[-2\left(\eta S_{c}-S_{m}\right)\right] \int_{r_{0}}^{r} \beta_{m}\left(r^{\prime}\right) d r^{\prime}}
$$

Where $X(r)=r^{2} P(r) / C_{a}$ is CALIOP attenuated backscatter from the atmosphere at the distance $\mathrm{r}$; $S_{c}=\sigma_{c}(r) / \beta_{c}(r)$ is cirrus cloud extinction to backscatter ratio and so-called lidar ratio, $S_{m}=8 \pi / 3$ is molecular extinction to backscatter ratio.

Cloud backscatter ratio BR is defined as:

$$
B R(r)=\frac{\beta_{c}(r)+\beta_{m}(r)}{\beta_{m}(r)}
$$

Where $\beta_{c}(r)$ and $\beta_{m}(r)$ are the backscatter coefficients of cloud and air at range $r$ respectively.

The bottom and top height of the cloud have been considered on the following criteria: (i) for the base height of cloud, $\mathrm{BR} \geq 1.5$ is used and this ratio should also Persists for at least 5 consecutive intervals of height range, so that the top height of cloud can be defined by considering $\mathrm{BR}=1.5$ and (ii) the height of cloud base should exceed $8 \mathrm{~km}$. The reason for choosing the backscattering ratio of 1.5 is mainly due to the fact that the cirrus should be clearly distinguished from the other fluctuating scattering ratio [12].
According to error analyses, when aerosol optical depth is small, the relative error of retrieved cirrus optical depth has a linear relationship with the relative error of cirrus extinction to backscatter ratio [13]. An empirical equation for determination of aerosol lidar ratio $S_{c}$ was developed as following [14]:

$$
a_{1} S_{c}+b_{2}=e^{-\left(a_{2} S_{c}+b_{2}\right)}
$$

Where parameters $a_{i}$ and $b_{i} \quad(\mathrm{i}=1,2)$ are least-square-fit coefficient and can be obtained by regression method, approximate solution of transcendental Eq. (4) yields an independent measurements cirrus lidar ratio $S_{c}$, the retrieved $S_{c}$ has non-relationship with the multiple scattering factor $\eta$ and cirrus transmission.

\section{RESULTS}

The retrieval results is shown in Fig.1, it is obvious that cirrus lidar ratio is nearly constant for different cirrus case occurrences, the overall mean value of cirrus lidar ratio for the area of over Longitude $120+/-10$ and Latitude $25+/-10$ is $21.66 \pm 0.06 \mathrm{sr}$, the mean bias is $0.27 \%$ with the maximum bias of $9.25 \%$ for the year 2008. It's shown that the retrieval of cirrus lidar ratio is stable and reasonable. This result is consistent with Min Min (24.1 $\pm 11.6 \mathrm{sr})$, Sassen and Comstock $(24.4 \pm 15.5 \mathrm{sr})$ and Vaughan $(23 \pm 9 \mathrm{sr})$ [15-17].

\section{CONCLUSION}

In this paper, a new method for retrieving cirrus lidar ratio is presented, the retrieval result is consistent with others' by using traditional method. This technique is suitable for cirrus lidar retrieval. 
One advantage is that this technique is not affected by the cirrus multiple scattering effects and the error of cirrus transmission determination.

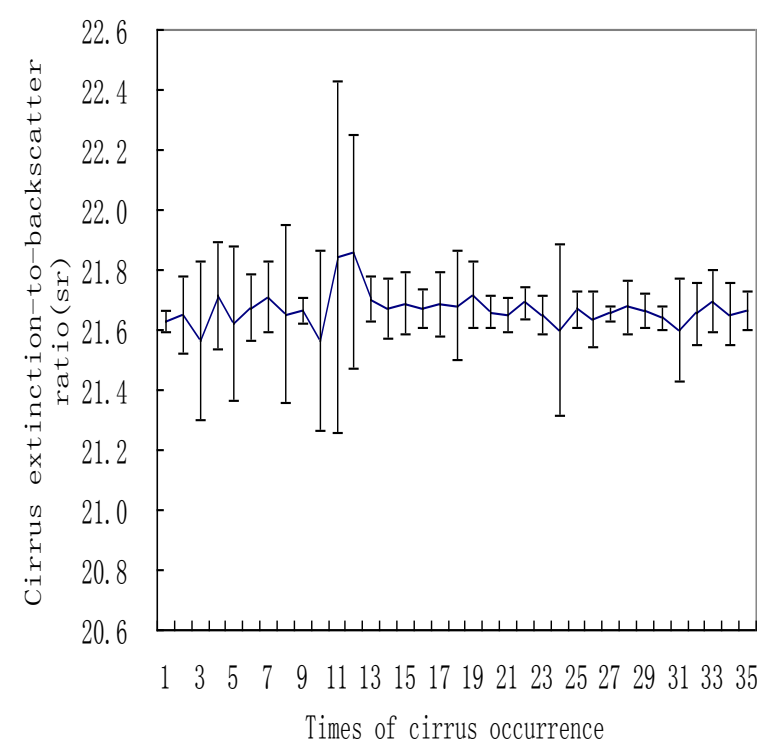

Fig.1 Retrieval results of cirrus extinction to backscatter ratio $(532 \mathrm{~nm})$ vs. times of cirrus occurrence for the year 2008.

\section{ACKNOWLEDGEMENT}

The authors wish to thank the CALIPSO team at NASA Langley Research Center for providing the data used in our calculations.

\section{REFERENCES}

[1] Barrett, E. W. and Ben-Dov, O., 1967: Application of the lidar to air pol lution measurements, J. Appl. Meteorol., 6, 500-515.

[2] Davis, P. A., 1969: The analysis of lidar signatures of cirrus clouds, Appl. Opt., 8, 2099-2102.

[3] Fernald, F. G., Herman, B. M., and Reagon, J. A., 1972: Determination of aerosol height distributions by lidar, J. Appl. Meteorol., 11, 482-489.

[4] Platt, C. M. R., 1973: Lidar and radiometric observations of cirrus clouds, J. Atmos. Sci., 30, 1191-1204.

[5] Platt, C. M. R., 1979: Remote sounding of high clouds. I: Of visible and infrared optical properties from lidar and radiometer measurements, J. Appl. Meteorol.,18, 1130-1143.

[6] Platt, C. M. R., Scott, J. C., and Dilley, C., 1987: Remote sounding of high clouds.Part VI: Optical properties, J. Atmos. Sci., 44, 729-747.

[7] Klett, J. D., 1981: Stable analytical inversion solution for processing lidar returns, Appl. Opt., 20, 211-220.

[8] Fernald, F. G, 1984: Analysis of atmospheric lidar observations; some comments, Appl. Opt., 23, 652-653,

[9] Ansmann A., Wandinger U., Riebesell M., Weitkamp C. and Michaelis W., 1992: Independent measurement of extinction and backscatter profiles in cirrus clouds by using a combined Raman elastic backscatter lidar, Appl. Opt., 31, 7113-7131.

[10] Takano, Y., and K.-N. Liou., 1995: Solar radiative transfer in cirrus clouds. Part III: Light scattering by irregular ice crystals, J. Atmos. Sci., 52, 818-837.

[11] Chen, W. N., Chiang, C. W., and Nee, J. B., 2002: Lidar ratio and de polarization ratio for cirrus clouds, Appl. Opt., 41, 6470-6476,.

[12] Subrata Kumar Das, Chih-Wei Chiang, and Jan-Bai Nee, 2008: Characteristics of cirrus clouds and its radiative properties based on lidar observation over Chung-Li, Taiwan, Atmos. Res. 93, 723-735.

[13] Jinhuan Qiu, Daren Lu, 1988: A study of inversion algorithm for determining atmospheric aerosol profile from simulated space-borne Lidar signals (in Chinese), Chinese J. Atmos. Sci., 12, 258-270. 
[14] Jingbin Zhang, 2008: A method for determination of aerosol extinction-to-backscatter ratio, In 24th International Laser Radar Conference (ILRC), Boulder, CO, USA.

[15] Min Min, Wang Pucai, Zong Xuemei, 2010: Extinction to backscatter ratio of cirrus clouds retrieved by spaceborne lidar over china, Chinese Journal of Atmospheric Sciences (in Chinese), 34, 506-512.

[16] Sassen K, Campbell J R. 2001: A midlatitude cirrus cloud climatology from the facility for atmospheric remote sensing, Part I: Macrophysical and Synoptic properties, J. Atmos. Sci., 58, 481-496.

[17] Vaughan M, Kuehn R, Young S, et al. 2008: Validating cirrus cloud optical properties retrieved by CALIPSO. In 24th International Laser Radar Conference (ILRC), Boulder, CO, USA. 